\title{
Improving supplychain performance in an online store using Lean tools
}

\author{
K. Sadesh ${ }^{1}$, A P Senthilkumar ${ }^{2}$ \\ $\left\{\right.$ ksh.mech@psgtech.ac.in ${ }^{1}$,aps.mech@psgtech.ac.in $\left.{ }^{2}\right\}$ \\ Department of Mechanical Engineering, PSG College of Technology ${ }^{1}$
}

\begin{abstract}
In today's scenario severe Competitive pressure for Shorter lead time and lower cost in Supply chain Management, So Lean manufacturing have been incorporated into Supply chain approaches. This Paper deals with Reduction of Customer lead time and Transportation cost in an online store. The Customer lead time reduced from 2.5 days to 1.5 days and transportation cost reduced from 1216 to 1136 for 11 orders with $63.9 \mathrm{~km}$ through lean supply chain network with vehicle routing (Travelling sales man approach), Inventory classification and Forecasting techniques.
\end{abstract}

Keywords: Lean Supply Chain Network; Travelling sales man approach; ABC analysis; Forecasting techniques.

\section{Introduction}

SCM refers to the management of physical items and services, information, and money between the activities or process stages that firms execute, with the purpose of providing excellent customer service (i.e., getting the right product to the right place at the right time for the right price). The firms and business activities required to create, manufacture, deliver, and use a product or service are referred to as supply chains. Businesses rely on their supply chains to get what they need to stay afloat and grow. Every company is a part of one or more supply chains, and each one has a specific role to perform.

A. Lean manufacturing

Lean is a systematic strategy to increasing customer value by finding and removing waste (of time, effort, and materials) through continuous improvement, and by flowing the product at the customer's pull in the pursuit of perfection.

\section{B. Lean SCM}

A new method of thinking about supplier networks is represented by lean SCM. Lean concepts necessitate collaborative supplier relationships that strike a balance between collaboration and competitiveness. Collaboration entails a variety of collaborative connections and coordinating techniques. Strategic alliances and supplier partnerships are important aspects of lean supply chain management.

\section{LITERATURE REVIEW}

${ }^{[1]}$ RamJanm Singh et al., suggested that lead time reduction attained through implementation of LJIT practices and SCI between with-in and between firms.

${ }^{[2]}$ MahtabHajghasem et al., discussed web-based system was created to allow the registration of handling requests in the system in order to compensate for vehicle shortages. The main purpose was to cover all transportation requests in a manner that it results in a reduced transportation cost, a reduced use of rental vehicles, and a reduced stopping duration of vehicle in destinations.

${ }^{[3]}$ Paul Myerson discussed in Lean logistics and SCM about Supply chain network design inorder to optimize the Procurement, Manufacturing,Transportation and Distribution.

${ }^{[4]}$ Reem Al Zoubi suggested that Generic Algorithm (GA) in an efficient way to arrive optimal solution. GA follows sequence of processes to solve any problem. Each of these processes has different varieties that can be chosen based on the problem's characteristics.

${ }^{[5]}$ M.Karthick et al., discussed that $\mathrm{ABC}$ classification is used to classify things so that each inventory category can be effectively controlled based on its importance rating. 
${ }^{[6]}$ Maine-Chun-Yu discussed about astudy that compared artificial intelligence-based classification techniques against traditional classification techniques.

${ }^{[7]}$ PradeeKumarSahu et al., discussed the importance of various forecastingmodels and their application for sales forecasting ofsterilized flavored milk in Chhattisgarh.

${ }^{[8]}$ Rachel J. C. Chen described, are readily transferable torecreation use data sets with seasonal patterns.

From the literature review Lean supply chainmanagement helps to preserve market stability by lowering operating costs and inventory levels, when implementing lean in supply chain approaches inonline stores which is viable to reduce Customer lead timeand transportation cost effectively.

\section{PROBLEM STATEMENT}

Company has more distributors for Electronicgadgets from various Locations. If a customer is placing anorder, for him/her to procure the item and store it ininventory which includes packaging and labelling accountsfor high customer lead time which is 2.5 days and involveshigh transportation cost. As demand and Price uncertaintyvarying day by day, managing inventory and faster servicelevel are difficult (i.e. Customer lead time).

\section{OBJECTIVES}

1. To develop lean supply chain network design in order toReduce Customer lead time

2. To reduce the transportation cost of vehicle route byusing Travelling salesman approach.

3. To analyze the inventory through ABC Classification

4. To implement forecasting techniques in order to predictthe future forecast.

\section{METHODOLOGY}

The Figure 1 shows the developing lean supply chainnetwork design in order to reduce high customer lead timeand Transportation cost.

\section{CUSTOMER LEAD TIME}

The customer lead time is calculated as 2.5 days. Figure 2 shows current customer lead time.

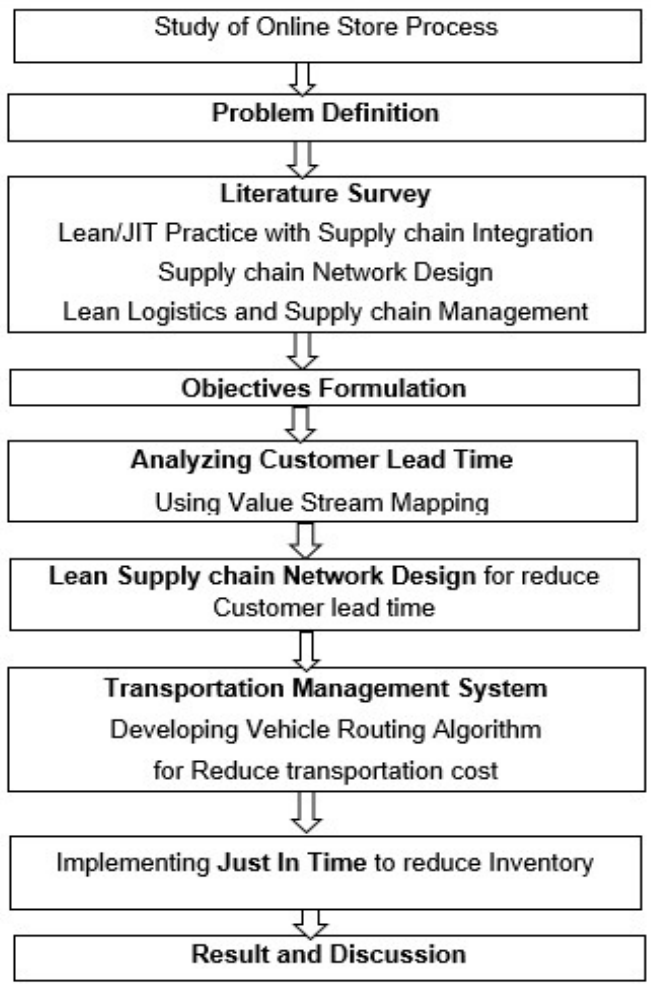

Figure 1. Methodology 
VII. LEAN SUPPLY CHAIN NETWORK

Lean supply chain network essential for make the supply chain decisions. Figure 3 shows frame work for lean supply chain Network design

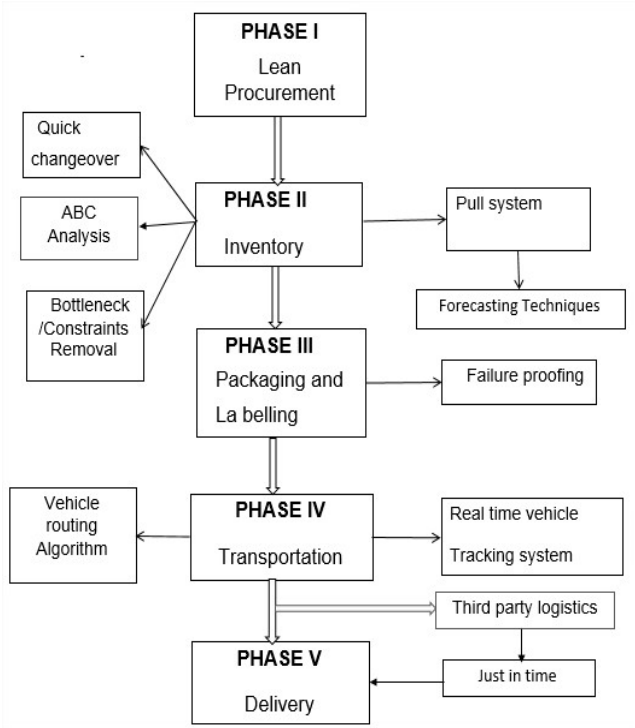

Figure 3. Lean supply chain network



Figure 2. Current State VSM for High Customer lead time

\section{A. Logistics Management}

Following figure 4 shows route cause for high transportation cost. For 11 orders total travelling distance is $77 \mathrm{KM}$ including service charge Rs 600 and Rs 8 per km total transportation cost was Rs 1216.

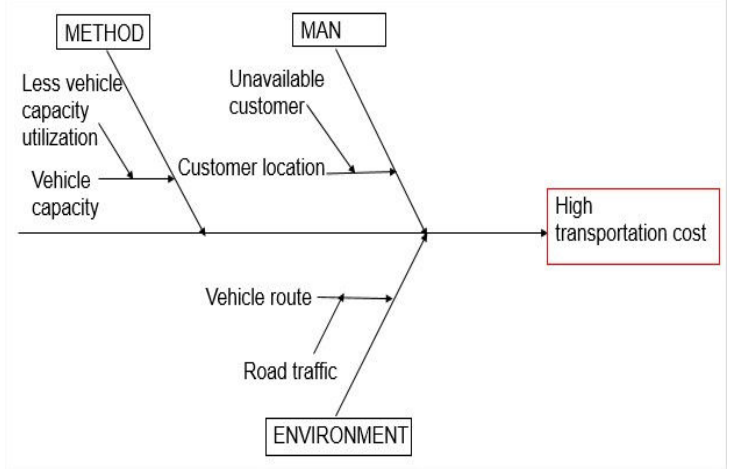


B. Mathematical model

Figure 4. Route Cause Analysis

Mathematical model is developed for Travelling Sales man approach which used to find out the minimumthe Travelling Distance

$$
\operatorname{MinZ}=\sum_{i=1}^{n} \sum_{j=1}^{n} D_{i j} x_{i j}
$$

Subjected to,

$$
\begin{array}{ll}
\sum_{i=1}^{n} x_{i j}=1, & j=1,2, \ldots, n \\
\sum_{j=1}^{n} x_{i j}=1, & i=1,2, \ldots, n \\
y_{i}-y_{j}+n x_{i j} \leq n-1 & \forall i \neq j \\
x_{i j}=0 \text { or } 1 & \forall i, j .
\end{array}
$$

Where

$\mathrm{n}=$ Number of customers

$\mathrm{D}_{\mathrm{ij}}=$ Distance of customer from $\mathrm{i}$ to $\mathrm{j}$

$\mathrm{x}_{\mathrm{ij}}=1$ Saleş man travels from $\mathrm{i}$ to $\mathrm{j}$

0 otherwise

$\mathrm{y}=\mathrm{Sub}$ tour avoiding variable for $\mathrm{i}^{\text {th }}$ and $\mathrm{j}^{\text {th }}$ customer

The variables $y_{i}, y_{j}$ are arbitrary real numbers which

satisfy the constrain (4) which helps to avoid the sub tours.

\section{Travelling Salesman Approach}

The following table1 shows distance between each customer.

Table 1. $\mathrm{D}_{\mathrm{ij}}$ Distance Matrix

\begin{tabular}{|l|l|l|l|l|l|l|l|l|l|l|}
\hline & $\mathbf{1}$ & $\mathbf{2}$ & $\mathbf{3}$ & $\mathbf{4}$ & $\mathbf{5}$ & $\mathbf{6}$ & $\mathbf{7}$ & $\mathbf{8}$ & $\mathbf{9}$ & $\mathbf{1 0}$ \\
\hline $\mathbf{1}$ & 0 & 4.7 & 16.5 & 13.1 & 10.4 & 6.8 & 6.8 & 7 & 10.1 & 13.4 \\
\hline $\mathbf{2}$ & 4.7 & 0 & 11.5 & 15 & 12.8 & 4.7 & 6.3 & 4.3 & 6.1 & 12 \\
\hline $\mathbf{3}$ & 16.5 & 11.5 & 0 & 23 & 19.2 & 12 & 14.2 & 18.7 & 9.7 & 12.3 \\
\hline $\mathbf{4}$ & 13.1 & 15 & 23 & 0 & 10.4 & 13 & 13.3 & 17.8 & 16.6 & 19.6 \\
\hline $\mathbf{5}$ & 10.4 & 12.8 & 19.2 & 10.4 & 0 & 7 & 6 & 13.8 & 11.7 & 8.9 \\
\hline $\mathbf{6}$ & 6.8 & 4.7 & 12 & 13 & 7 & 0 & 1.8 & 9 & 4.7 & 6.3 \\
\hline $\mathbf{7}$ & 6.8 & 6.3 & 14.2 & 13.3 & 6 & 1.8 & 0 & 8.5 & 6.3 & 7.3 \\
\hline $\mathbf{8}$ & 7 & 4.3 & 18.7 & 17.8 & 13.8 & 9 & 8.5 & 0 & 9.4 & 15.4 \\
\hline $\mathbf{9}$ & 10.1 & 6.1 & 9.7 & 16.6 & 11.7 & 4.7 & 6.3 & 9.4 & 0 & 8.6 \\
\hline $\mathbf{1 0}$ & 13.4 & 12 & 12.3 & 19.6 & 8.9 & 6.3 & 7.3 & 15.4 & 8.6 & 0 \\
\hline
\end{tabular}

Using travelling salesman approach with evolutionarymethod shortest path and the total distance are calculated.

Optimized path is,

\begin{tabular}{|l|l|l|l|l|l|l|l|l|l|}
\hline 4 & 5 & 7 & 6 & 10 & 3 & 9 & 2 & 8 & 1 \\
\hline
\end{tabular}

Total travelling distance $=$

$10.4+6+1.8+6.3+12.3+9.7+6.7+4.3+7+0$

$=63.9 \mathrm{KM}$

D. Algorithm to Calculate Transportation cost in Vehicle Routing

Terminology:

Number of Order $\quad=\mathrm{n} 1$

Optimized Distance $=$ do

Total service charge $=\mathrm{cs}$

Cost per KM = ckm

Number of customer $\quad=\mathrm{nc}$ 


$\begin{array}{ll}\text { Number of vehicle } & =\mathrm{v} 1 \\ \text { Capacity of vehicle } & =\mathrm{cv} \\ \text { Number of delivery person } & =\mathrm{d} 1 \\ \text { Rental vehicle cost } & =\mathrm{rc} \\ \text { Transportation cost } & =\mathrm{tc}\end{array}$

Step 0: Initialize and store $\mathrm{n} 1, \mathrm{do}, \mathrm{cs}, \mathrm{ckm}, \mathrm{nc}, \mathrm{cv}, \mathrm{d} 1, \mathrm{v} 1$ and $\mathrm{rc}$.

Step 1: Compute Number of customer nc.

Step 2: Compute do and tc

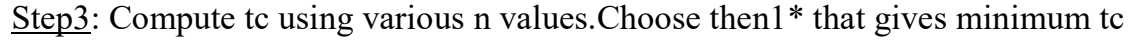

Step 4: Stop

The simulation was done in mat lab and result is shown infollowing figure 5.

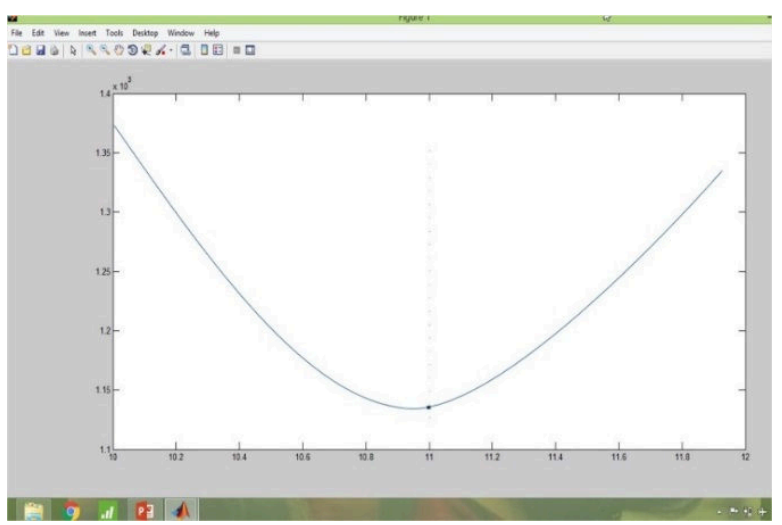

Figure 5.Mat lab result for Transportation Cost

\section{INVENTORY CLASSIFICATION}

Table 2 shows ABC Classification based on the Cost and Usage value of the product.Figure 6 shows process flow of $\mathrm{ABC}$ analysis

Table 2. Inventory classification

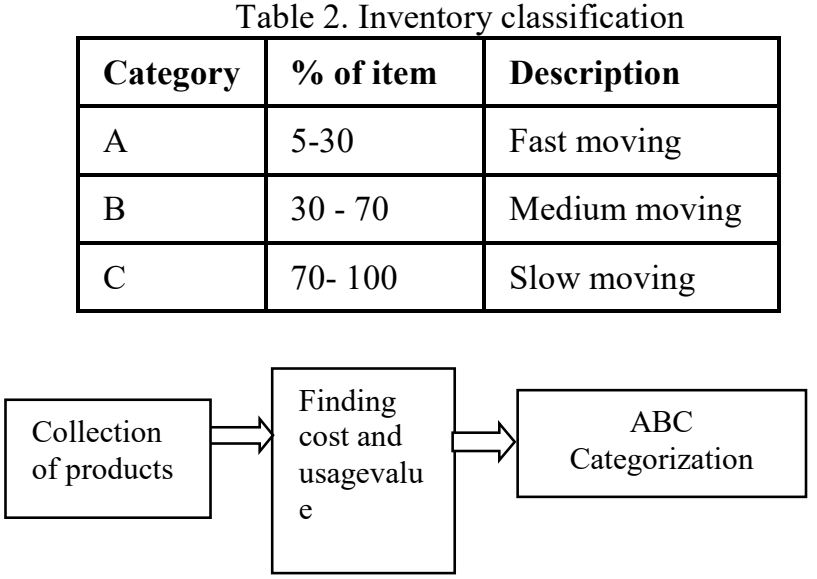

Figure 6.Process flow of ABC analysis

Figure 7 shows moving range of inventory items 0.3 to $30 \%$ Headphones, Pen drives, Memory cards A items and 30 to $67 \%$ Mother boards, PC ram, Laptop Ram. B items and 70to $100 \%$ Graphics card, Cables, Speakers, SMPS, Monitors, Processor C items. 


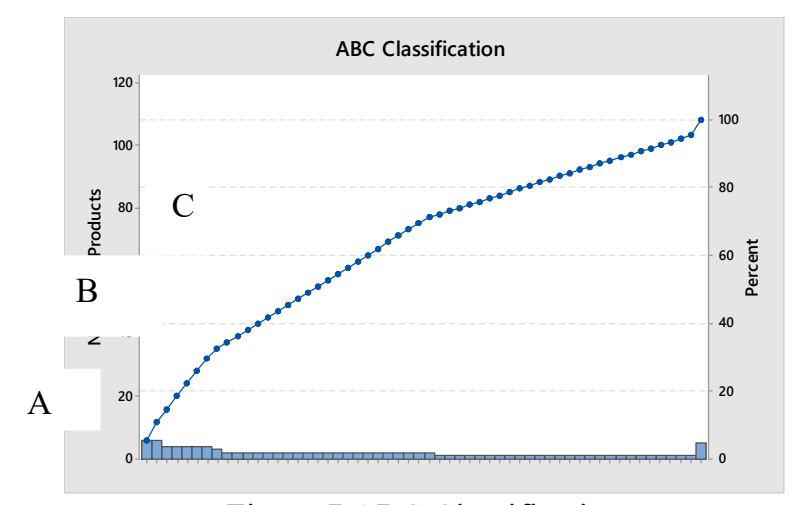

IX. FORECASTING TECHNIQUES

Figure 7.ABC Classification

Forecast of future demand are essential for making supply chain decisions.Various forecasting techniques that helps to predict the forecasting accuracy were used

Table 3 shows demand data about 18 weeks from December 2017 to February 2018.

Table 3. Demand data

\begin{tabular}{|l|l|}
\hline Week No & Demand \\
\hline $\mathbf{1}$ & $\mathbf{3 5}$ \\
\hline 2 & $\mathbf{8 1}$ \\
\hline 3 & $\mathbf{5 7}$ \\
\hline $\mathbf{3}$ & $\mathbf{4 6}$ \\
\hline $\mathbf{5}$ & $\mathbf{6 4}$ \\
\hline $\mathbf{6}$ & $\mathbf{5 3}$ \\
\hline 7 & 49 \\
\hline 8 & $\mathbf{6 4}$ \\
\hline $\mathbf{9}$ & $\mathbf{4 5}$ \\
\hline 10 & $\mathbf{5 8}$ \\
\hline 11 & 72 \\
\hline 12 & $\mathbf{5 7}$ \\
\hline 13 & 61 \\
\hline 14 & $\mathbf{5 9}$ \\
\hline 15 & 47 \\
\hline 16 & $\mathbf{7 4}$ \\
\hline 17 & $\mathbf{5 6}$ \\
\hline 18 & 63 \\
\hline
\end{tabular}

A. Simple moving Average

Using theSimple moving Forecast formula Average error rate is calculated Average period 9, MAD 7, MSE 85. Figure 8 shows demand and Forecast range

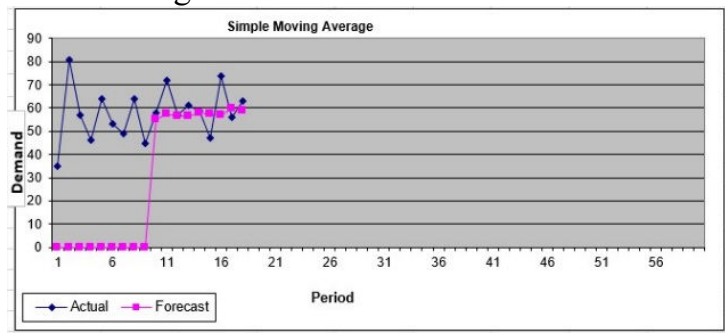

Figure 8.Simple Moving Average

B. Simple Exponential smoothing method

Using the Simple Exponential smoothing Forecast formula Average error rate is calculated Smoothing Constant $\alpha=0.2, \mathrm{MAD}=13, \mathrm{MSE}=295$.Figure 9shows Demand and Forecast range. 


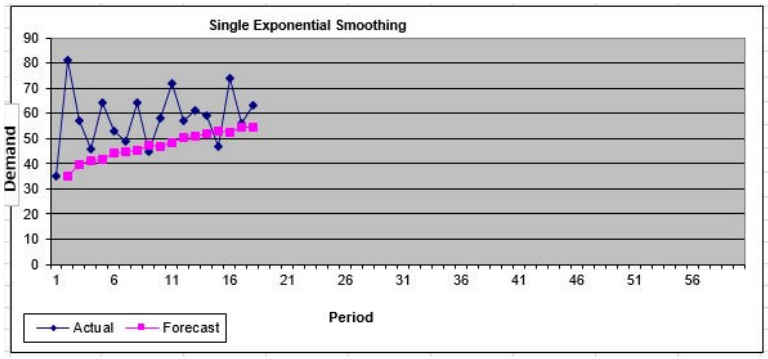

Figure 9. Simple Exponential smoothing

C. Weighted Moving Average

Using the Weighted movingForecast formula Average error rate is calculated MAD 6, MSE 67. Figure 10shows Demand and Forecast range.

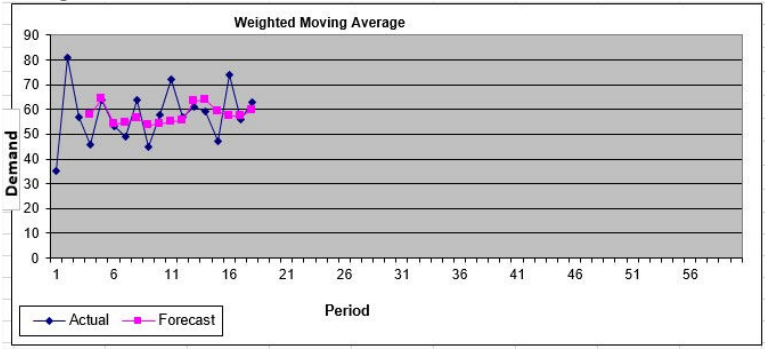

Figure 10. Weighted Moving Average

D. Trend Adjusted Exponential Smoothing

Using the Trend Adjusted Exponential Smoothing Forecst formula Average error rate is calculated Smoothingcostant $\alpha$ 0.2, Smoothing constant $\delta$ 0.5, MAD 11, MSE 246. Figure 11 shows Demand and Forecast range.

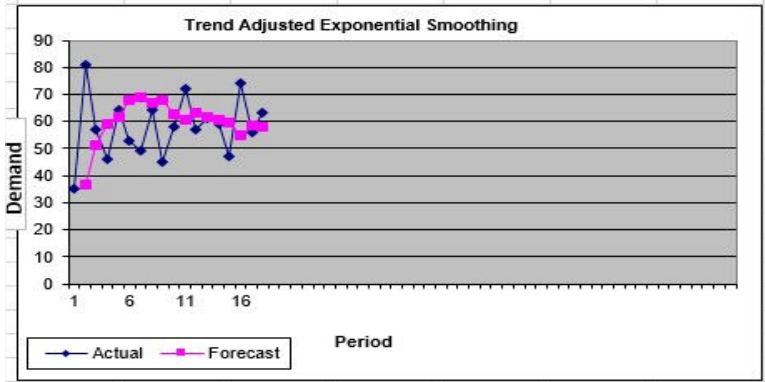

Figure 11. Trend Adjusted Exponential Smoothing

\section{E. Linear Trend}

Using the Linear Trend Forecast formula Average error rate is calculated slopem 0.43 , Intercept y 53.71, MAD 7, MSE 70. Figure 12 shows Demand and Forecast range.

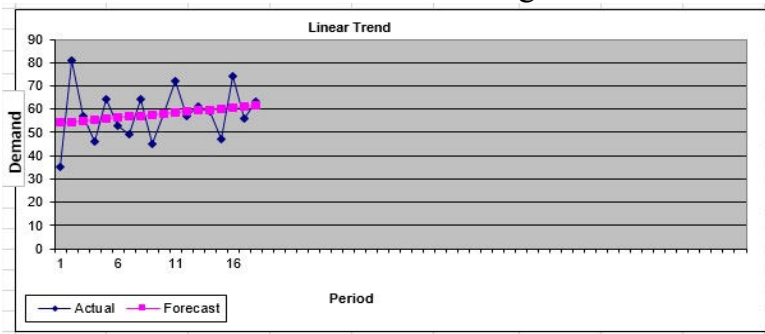

Figure 12. Linear Trend

The following table 4 shows overall error rate of the forecasting techniques

Table 4. Average Error rate

\begin{tabular}{|l|l|l|}
\hline Method & \multicolumn{2}{|l|}{ Error rate } \\
\hline \multirow{2}{*}{ Simple Moving Average } & MAD & 7 \\
\cline { 2 - 3 } & MSE & 80 \\
\hline Exponential Smoothing & MAD & 6 \\
\hline
\end{tabular}




\begin{tabular}{|l|l|l|}
\hline & MSE & 73 \\
\hline \multirow{2}{*}{$\begin{array}{l}\text { Weighted Moving } \\
\text { Average }\end{array}$} & MAD & 13 \\
\cline { 2 - 3 } & MSE & 295 \\
\hline \multirow{2}{*}{$\begin{array}{c}\text { Trend Adjusted } \\
\text { Exponential Smoothing }\end{array}$} & MAD & 11 \\
\cline { 2 - 3 } & MSE & 246 \\
\hline \multirow{2}{*}{ Linear Trend } & MAD & 7 \\
\cline { 2 - 3 } & MSE & 70 \\
\hline
\end{tabular}

\section{RESULTS AND DISCUSSION}

\section{A. Transportation Cost}

Transportation cost for 11 orders and $63.9 \mathrm{~km}$

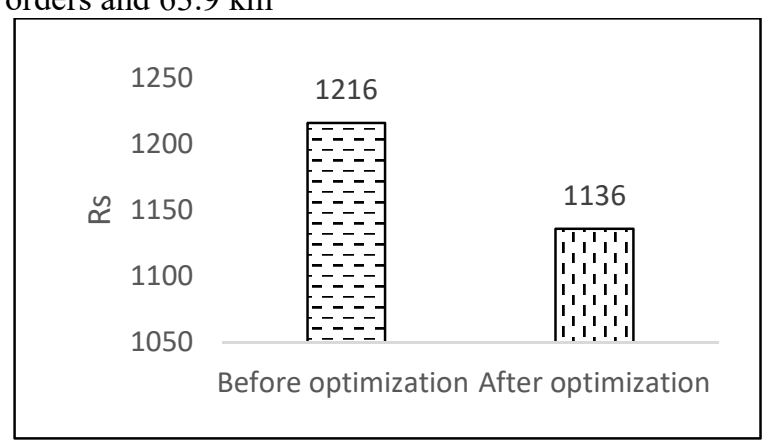

Figure 13. Transportation cost

\section{B. ABC Classified Items}

The categorized item shows that item which we can kept on minimal Inventory Table 5 results ABC categorized items

Table 5. ABC Classification

\begin{tabular}{|l|l|l|}
\hline Sequence & Products & Category \\
\hline $\begin{array}{l}0.3 \\
30 \%\end{array}$ to & $\begin{array}{l}\text { Headphones, } \\
\text { Monitors,Memorycards }\end{array}$ & $\mathrm{A}$ \\
\hline $\begin{array}{l}30 \% \text { to } \\
67 \% \text { Pother boards, PC ram, } \\
\text { Laptop, Ram }\end{array}$ & $\mathrm{B}$ \\
\hline $00 \%$ & $\begin{array}{l}\text { Graphics } \\
\text { card,Cables,Speakers,SMPS,Pe } \\
\text { ndrives, Processor }\end{array}$ & $\mathrm{C}$ \\
\hline
\end{tabular}

\section{Future state VSM for customer lead time}

Inventory classification, vehicle routing and third party logistics are used to in lean supply chain network to reduce customer lead time; the following figure 14 shows Future state VSM for customer lead time. 


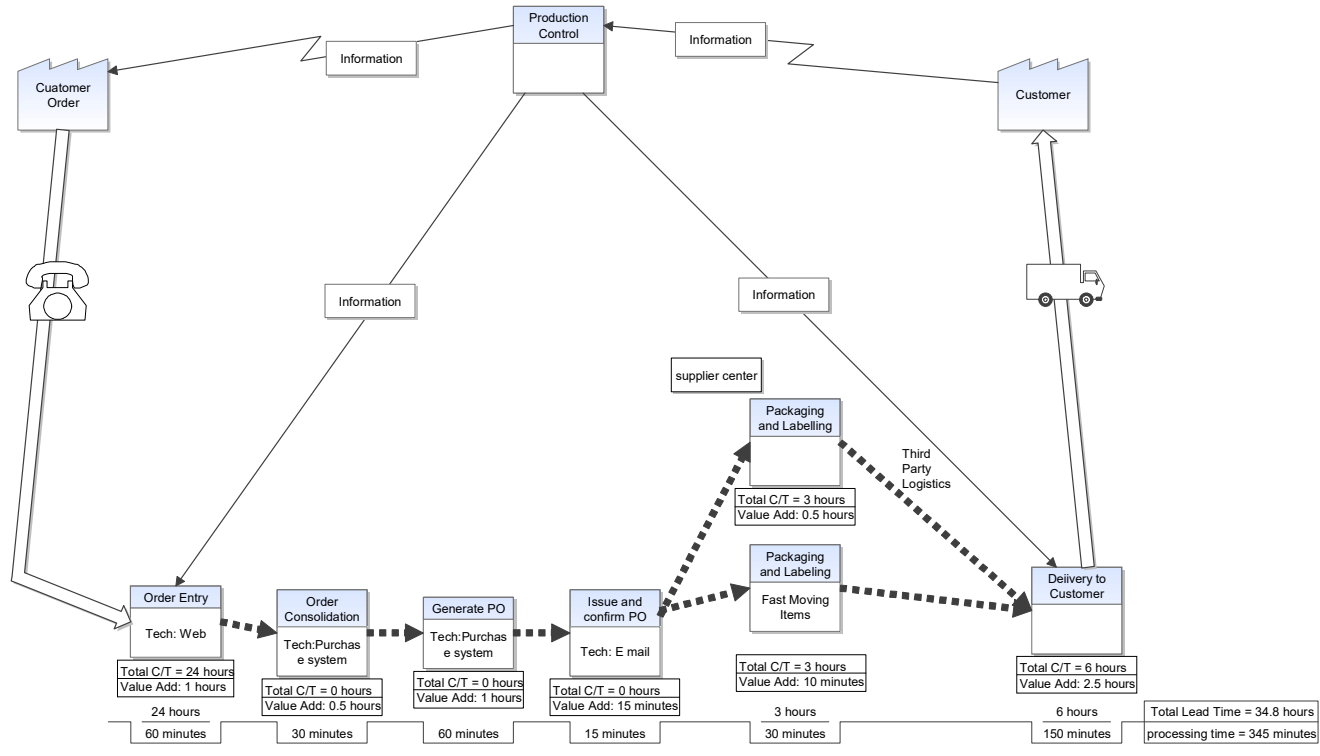

Figure 14.Future State VSM for Reduction of High lead time

D. Forecasting demand

Single Exponential Smoothing and linear trend more confident and also lowest error rate which will helps to put Sales discount on Seasonal period and Manage forecasting accuracy following figure11 shows Error range of forecasting techniques.

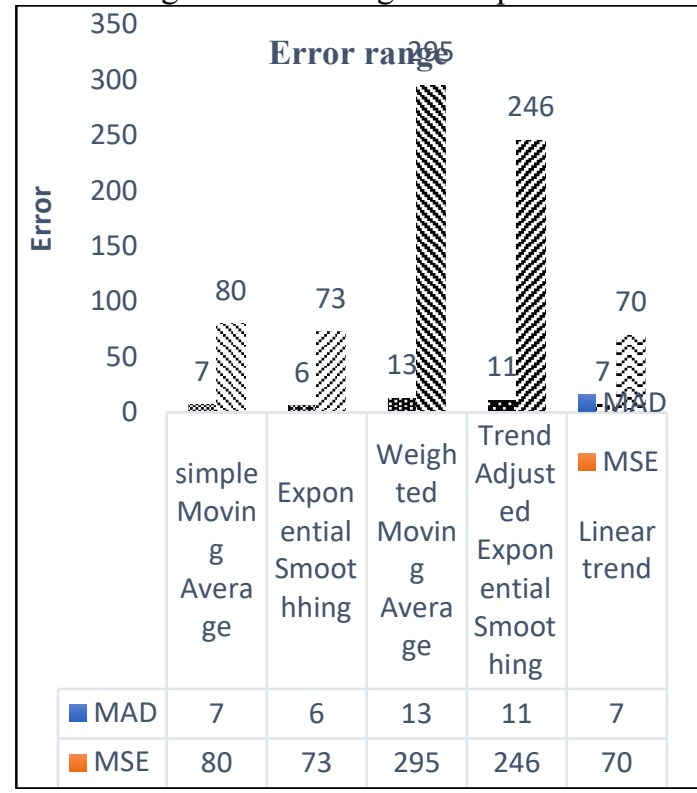

Figure 11. Error range 


\section{Conclusion}

The Customer Lead time was reduced from 2.5 days to 1.5 days and also the transportation cost also reduced for 11 orders with $63.9 \mathrm{~km}$ from Rs 1216 to Rs1136.The inventory classification helps us to keep minimal inventory for Fast moving items. The forecasting method helps to predict the forecasting accuracy for the future demand.

\section{References}

[1] Ram janm sigh, Nagendra, Hemant Marmat., "Effect of lean /JIT practices and supply chain Integration on lead time performance" Journal of supply chain management system, volume 2. pp 345-352,Mar 2013

[2] MahtabHajghasema, Amir Abbas shojaie.,"Optimal Routing in Supply Chain Aimed at Minimizing VehicleCost and Supply" Procedia Economics and Finance .pp 353 - 362, 2016.

[3] Paul Myerson "Lean logistics and supply chainmanagement”McGrawhill books, 2012.

[4] Recon A, Zoubia., "Travelling sales man approach" International journal of computer application".Volume 94, 2014.

[5] M. Karthick, S. Karthikeyan and M.C. Pravin.,"A Model for Managing and Controlling the Inventory of Stores Items based on ABC Analysis" Global Journal of Researches in Engineering. Volume 14, 2014

[6] Maine-Chun-Yu., "The artificial intelligence for multiple criteria ABC analysis", Global Journal of Researches in Engineering. Volume 9, 2010.

[7] Pradeep Kumar Sahu, Rajesh Kumar, "The Evaluation of Forecasting Methods for Sales of Sterilized Flavoured Milk in Chhattisgarh". International Journal of Engineering Trends and Technology (IJETT).Volume no.8, 2014.

[8] Rachel J. C. Chen." "Evaluation of alternative forecasting methods to recreation", International Journal of Engineering Trends and Technology (IJETT).Volume no9, 2015.

[9] M. Tholkapiyan, A.Mohan, Vijayan.D.S , "A survey of recent studieson chlorophyll variation in Indian coastal waters", IOP Conf. Series: Materials Science and Engineering 993 (2020) 012041, doi:10.1088/1757-899X/993/1/012041. 